\title{
Monte compartido, monte dividido. Apropiación y gestión de un paisaje de montaña: Los seles de la sierra de Hernio (País Vasco), siglos XIV-XIX
}

Josu Narbarte, Ander Rodríguez-Lejarza, Eneko del Amo, Asier Olazabal, ENEKo IRIARTE Y JUAN ANTONIO QUIRÓS

PALABRAS CLAVE: paisaje de montaña, bienes comunales, gestión forestal, arqueología de época moderna.

CÓDIGOS JEL: N53, Q15, Q23, R14.

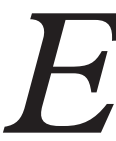

l paisaje de montaña es reflejo de la interacción histórica entre los grupos humanos y su medio ambiente. Esta relación se establece a través de prácticas, derivadas de relaciones sociales, que se orientan a la apropiación y gestión de los recursos. Este trabajo propone reconsiderar los paisajes de montaña de la vertiente cantábrica vasca como espacios altamente antropizados, caracterizados por la intersección constante de actores y prácticas. Para ello, se realiza un análisis microlocal intensivo, centrado en los seles de la sierra de Hernio (Gipuzkoa) en los siglos XIV-XIX. La combinación de fuentes, toponimia y prospección arqueológica permite reconocer las huellas de diferentes procesos históricos. Éstos están ligados a los mecanismos de gestión colectiva, al arbitraje para resolver conflictos y a la regulación de aprovechamientos. El estudio contribuye a superar la aparente ilegibilidad de un paisaje muy fragmentado y diversificado. 


\title{
Common mountain, divided mountain. The appropriation and management of a mountain landscape: The seles of mount Hernio (Basque Country), fourtenth-nineteenth centuries
}

\author{
KEYWORDS: mountain landscape, common land, forestry, modern \\ period archaeology.
}

JEL CODES: N53, Q15, Q23, R14.

$14 \begin{aligned} & \text { ountain landscapes reflect the interaction between human groups and their } \\ & \text { environment. This relation relies on social practices aimed at the appro- } \\ & \text { priation and management of mountain resources, like agriculture, forestry, }\end{aligned}$ and husbandry. This paper proposes a reconsideration of mountain landscapes in the Atlantic sector of the Basque Country as highly anthropized spaces, defined by a constant intersection of social actors and practices. The combined study of documentary sources, toponymy and a surficial archaeological survey allows for the recognition of different historical processes. These are linked to collective management of mountain resources, arbitration as a mean of conflict resolution, or regulation of diverse and complementary land uses. All this has permitted to partially overcome the apparent illegibility of a highly diversified and fragmented landscape.

Recepción: 2019-12-30 - Revisión: 2020-05-30 - Aceptación: 2020-06-17

Josu Narbarte [orcid.org/0000-0002-0297-8526] es miembro de la Sociedad de Ciencias Aranzadi e investigador del Erdi Aroko Arkeologiaren, Ondaregintzaren eta Kultur Paisaien inguruko Ikerketa Taldea en la UPV/EHU. Dirección para correspondencia: Sociedad de Ciencias Aranzadi/Aranzadi Zientzia Elkartea, Zorroagagaina kalea, 11, 20014 Donostia/San Sebastián (España).C.e.:njnarbarte@aranzadi.eus

Ander Rodríguez-Lejarza [orcid.org/0000-0002-9050-8953] es investigador predoctoral en la UPV/EHU. Dirección para correspondencia: Departamento de Geografía, Prehistoria y Arqueología, Francisco Tomás y Valiente, 01006 Vitoria-Gasteiz (España).C. e.: arodriguezlejarza@gmail.com

Eneko del Amo [orcid.org/0000-0003-2359-0704] es miembro de la Sociedad de Ciencias Aranzadi. Dirección para correspondencia: Aranzadi Zientzia Elkartea, Zorroagagaina kalea, 11, 20014 Donostia/San Sebastián (España).C.e.: enekodelamo@gmail.com

Asier Olazabal es miembro de la Sociedad de Ciencias Aranzadi. Dirección para correspondencia:Aranzadi Zientzia Elkartea, Zorroagagaina kalea, 11, 20014 Donostia/San Sebastián (España). C. e.: sarrimov@hotmail.com Eneko Iriarte [orcid.org/0000-0001-8365-5616] es profesor contratado doctor en la Universidad de Burgos, Laboratorio de Evolución Humana. Dirección para correspondencia: Departamento de Geografía, Historia y Comunicación, Edificio I+D+i, plaza Misael Bañuelos, s/n, 09001 Burgos (España). C. e.: eiriarte@ubu.es

Juan Antonio Quirós [orcid.org/0000-0002-4676-102X] es catedrático de Arqueología en la UPV/EHU e investigador del Erdi Aroko Arkeologiaren, Ondaregintzaren eta Kultur Paisaien inguruko Ikerketa Taldea. Dirección para correspondencia: Micaela Portilla ikergunea, fusto Vélez de Elorriaga kalea, 1, 01006 Vitoria-Gasteiz (España).C.e.:quiros.castillo@ehu.eus 


\section{INTRODUCCIÓN}

Las últimas décadas han sido testigo de una profunda renovación en el estudio de los paisajes rurales en toda Europa. Esta renovación es el resultado de la convergencia de varios factores, entre los que destacan la acción positiva de la arqueología preventiva, que ha generado un enorme volumen de nuevos datos; la revisión de los paradigmas historiográficos dominantes; la construcción de nuevas agendas de investigación o la creación de nuevos proyectos de intervención patrimonial, anclados en una dimensión social de la labor investigadora. En este contexto, los trabajos desarrollados en numerosas regiones europeas han puesto de relieve la complejidad que caracteriza el paisaje rural, entendido este como la síntesis de largos procesos históricos en los que juega un papel crucial la codificación de distintas formas de apropiación y gestión de los recursos ${ }^{1}$.

Así, en varios países del sur de Europa se viene desarrollando una arqueología en la montaña, entre cuyos referentes principales destacan diversos proyectos ejecutados en el Pirineo por las Universidades de Toulouse, Pau o Autònoma de Barcelona, así como por el Grup de Recerca d'Arqueologia del Paisatge del Institut Català d'Arqueologia Clàssica (e.g. Bal et al., 2010; Galop et al., 2011; Rendu, 2003; Rendu et al., 2015, 2016; Gassiot, 2016; Gassiot \& Pèlachs, 2017; Palet et al., 2017). También son referenciales los trabajos desarrollados por el Laboratorio di Archeologia e Storia Ambientale de la Universidad de Génova en los Apeninos de Liguria (e.g. Moreno, 1990; Cevasco, 2007; Cevasco \& Molinari, 2007; Stagno, 2016, 2017, 2018), o el proyecto «Mediterranean Mountain Landscapes», recientemente desarrollado en paisajes de montaña de Andalucía, el Véneto, la Apulia y Albania ${ }^{2}$.

Por otra parte, entre los proyectos que integran el estudio de los espacios de montaña en una perspectiva más amplia, centrada en el paisaje rural en su conjunto, vale la pena citar la experiencia de las universidades de León y Oviedo en diferentes contextos asturianos (e.g. Fernández Mier, 1995, 1996, 2013; Fernández Mier \& Fernández Hevia, 1998; Fernández Mier et al., 2014, 2019; Fernández Fernández, 2011, 2017; Fernández Fernández, Moshenska \& Iriarte, 2017). En el País Vasco, se han desarrollado trabajos similares en las sierras de Aralar (e.g. Mujika, Moraza \& Moro, 2003; Mujika \& Moraza, 2005) y Aizkorri (e.g. Stagno \& Tejerizo, 2017; Stagno, 2019), así como en los montes deVitoria (e.g., Martínez Montecelo \& Rodríguez Fernández, 2013). Entre las propuestas teóricas y metodológicas planteadas por muchos de estos proyectos, destaca el énfasis

1. Pueden consultarse, en este sentido, las actas de los diferentes congresos sobre arqueología del paisaje que se han venido celebrando desde 2010 (https://iala-lac.org/) [Consulta: 18/12/2019].

2. «MEMOLA Project» (memolaproject.eu) [Consulta: 18/12/2019]. 
puesto en la implementación de estudios locales de alta resolución, basados en un análisis multidisciplinar y en una perspectiva diacrónica. Este tipo de enfoques permite caracterizar con la complejidad que requieren los modos de interacción entre las sociedades rurales y los recursos presentes en el medio, especialmente en contextos «marginales» como la montaña, cuyo carácter de espacio históricamente producido rara vez llega a ponerse en valor.

Sobre esta base se viene trabajando en los últimos años desde el Grupo de Investigación en Patrimonio y Paisajes Culturales de la Universidad del País Vasco/Euskal Herriko Unibertsitatea (UPV/EHU) en el estudio de las dinámicas de apropiación y gestión de los recursos de montaña en un sector central del territorio histórico de Gipuzkoa, la sierra de Hernio, con el fin de documentar: a) las formas de apropiación y reivindicación de la jurisdicción sobre este tipo de espacios; y b) el impacto de las distintas prácticas de gestión de los recursos en la transformación del paisaje.

En este trabajo, nos centraremos de manera particular en los seles situados en este entorno. Estos, denominados saroiak o kortak en euskera, constituyen un tipo de entidad espacial muy extendido en el País Vasco y el Pirineo occidental (Zaldua, 2015), aunque no son en absoluto exclusivos de dicha región Los seles son espacios acotados y demarcados en el monte, generalmente de morfología circular y dimensión variable (Fig. 1), situados, en función de su rendimiento principal, a diferentes alturas. Su singularidad reside en que, a pesar de constituir bienes de uso privativo -ya sea en manos de una comunidad o de un particular, a menudo de élites laicas e instituciones eclesiásticas-, se encuentran incluidos dentro de los límites de las tierras comunales de una comunidad; por lo tanto, su organización y explotación, aunque privativa, estaría regida por una serie de normas y sujeta a complejos juegos de conflicto y negociación.

Aunque diversas investigaciones arqueológicas han sugerido que este tipo de entidades espaciales podrían haber estado en uso desde, al menos, el siglo II (Zaldua 1996) ${ }^{3}$, el primer testimonio claro de la existencia de seles son varias menciones documentales del siglo IX (Díaz de Durana, 2001). Como veremos a lo largo de este trabajo, los límites de estos espacios, así como su gestión, fueron objeto de conflicto y transformación a lo largo de la Edad Moderna, lo que se traduce en una pervivencia muy desigual de sus huellas en el paisaje actual.

3. Se trataría de los resultados de las pruebas de carbono 14 realizadas sobre muestras de carbón procedentes de la base de un mojón delimitador de un sel en el término municipal de Urnieta (Gipuzkoa) (ZALDUA, 1996). 


\section{FIGURA 1}

\section{Ejemplos «clásicos» de seles en la vertiente cantábrica del País Vasco}
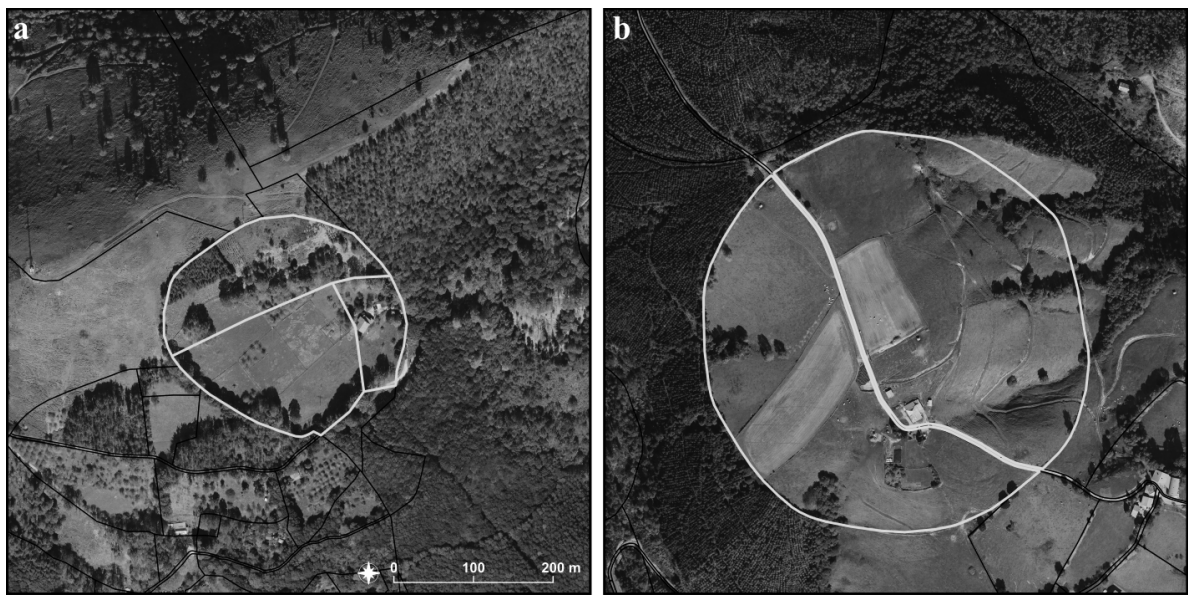

Nota: (a) sel de Akola (Hernani, Gipuzkoa), en los Montes Francos del Urumea; (b) sel de Makoleta (Arrieta, Bizkaia).

Fuente: elaboración propia a partir de las bases cartográficas del Centro Nacional de Información Geográfica, la Diputación Foral de Bizkaia y la Diputación Foral de Gipuzkoa.

Los textos medievales suelen citarlos como un elemento constitutivo de los sistemas locales de ganadería estacional, aunque su estructura de propiedad, usos y formas de gestión se fueron diversificando de manera notable con el tiempo (Etxezarraga \& Aragón, 2020). Estudios recientes han mostrado que, en el caso concreto de la vertiente cantábrica del País Vasco, los seles tuvieron una enorme relevancia en las estrategias económicas de comunidades, élites nobiliarias e instituciones eclesiásticas; estrategias que constituyen un factor clave en la transformación histórica del paisaje de montaña (e. g. Ugarte, 1976; Díaz de Durana, 1998, 2001; Aragón, 2009; Gogeascoechea, Juaristi \& Moro, 2009, 2010, 2011; Gogeascoechea, 2012).

Tal y como se desarrolla en las páginas que siguen, el estudio planteado combina el análisis de las fuentes documentales, etnográficas y toponímicas con una prospección arqueológica extensiva sobre el terreno. Los resultados se presentarán atendiendo a dos cuestiones diferentes. En primer lugar, prestaremos atención a las formas de apropiación y reivindicación de estos espacios compartidos en el curso de cuatro siglos, a partir de las evidencias documentales y toponímicas. En segundo lugar, centraremos el análisis en la evolución de los distintos usos y prácticas desarrolladas en estos espacios, y en las huellas dejadas por estas en el paisaje. Finalmente, el último apartado de conclusiones se ocupará de definir las principales pautas que se derivan del análisis combinado de ambas aproximaciones. 


\section{MATERIALES Y METODOLOGÍA}

\section{1. Área de estudio: la sierra de Hernio (Gipuzkoa)}

\section{FIGURA 2}

\section{Localización del área de estudio}

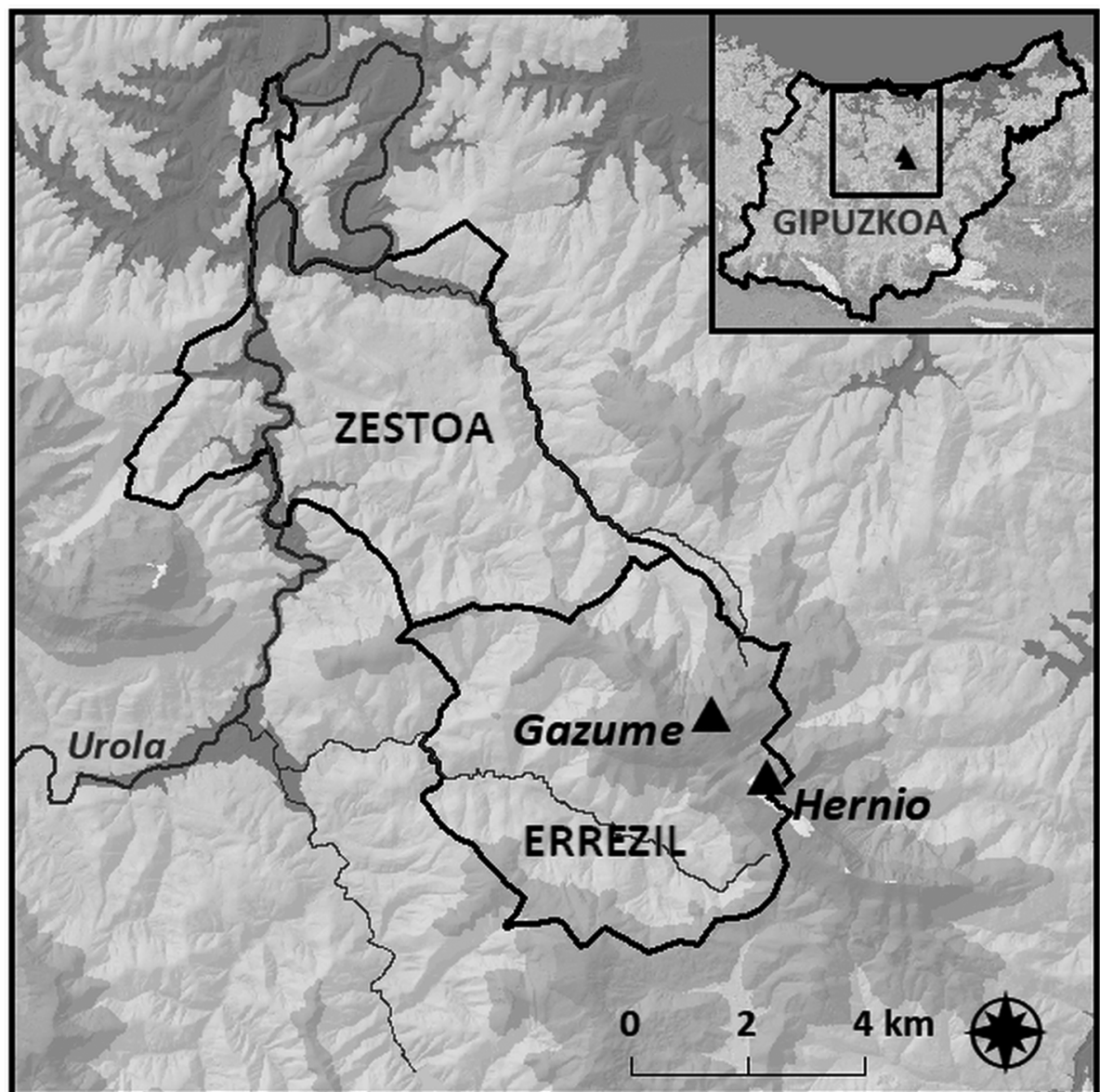

Fuente: elaboración propia a partir de la base cartográfica del Centro Nacional de Información Geográfica.

Los trabajos se han centrado en el sector septentrional de la sierra de Hernio (Gipuzkoa), en los términos municipales de Zestoa y Errezil (Fig. 2). Este espacio se caracteriza por la gran diversidad de actores y prácticas que convergen en su seno, entre las que destacan las relaciones particulares establecidas para con un conjunto de espacios cuya propiedad fue compartida por los concejos de Zestoa y Errezil entre los siglos XV y XIX. 
A diferencia de otras zonas cercanas, como las sierras de Aizkorri y Aralar, caracterizadas por un paisaje de alta montaña alejado de los principales lugares de habitación, Hernio presenta una estrecha integración con las dinámicas que han operado en los pueblos cercanos, tanto en los adyacentes valles del Oria y del Urola como la propia costa cantábrica. Por este motivo, no es posible, ni conveniente, realizar una distinción neta entre espacios de montaña y de valle, sino que ambos han de ser considerados como un continuum en el que prácticas y relaciones se cruzan e interactúan de manera constante.

Desde un punto de vista fisiográfico, la sierra de Hernio se compone de materiales del Cretácico inferior, fundamentalmente areniscas silíceas, calizas y lutitas, que forman una topografía accidentada con desniveles muy pronunciados. Las cimas de Hernio (1078 m) y Gazume (1001 m) se encuentran separadas por el collado de Zelatun $(841 \mathrm{~m})$. Desde 2013, este espacio se halla englobado en la Zona de Especial Conservación (ZEC) Hernio-Gazume, incluida también en la Red Natura 2000 con la denominación ES2120008. Abarca una superficie total de 2.158 hectáreas, caracterizadas por una amplia diversidad ecosistémica. En la actualidad, solo el 3,8\% de este espacio es de titularidad pública y se corresponde principalmente con zonas de roquedos calcáreos, difícilmente accesibles y poco adecuadas para cualquier aprovechamiento humano. El resto de la sierra se encuentra dividido en una miríada de parcelas de pequeño tamaño y titularidad privada, en las que predominan los usos forestales, los pastos de altura y, en las zonas más bajas de la sierra, las superficies agrarias organizadas en torno a un caserío disperso, localmente conocido como baserria.

Tal y como se desprende de esta diversidad de usos y unidades de paisaje, la historia de los espacios de montaña en el territorio guipuzcoano presenta singularidades propias. A diferencia de otras áreas cercanas como Araba, donde la pauta ha sido el mantenimiento de un sistema de aldeas basado en la gestión colectiva del comunal, en la vertiente cantábrica del País Vasco parece haber predominado una situación mucho más dinámica, caracterizada por una diversidad de actores e intereses, en ocasiones contrapuestos, y una marcada conflictividad en torno a los recursos forestales y de montaña, con una temprana desagregación de las prácticas de gestión colectiva (Aragón, 2001). Este territorio constituye, por tanto, un buen ejemplo para estudiar los procesos de transformación social y económica que recorrieron Europa a lo largo de la Edad Moderna.

En este sentido, el sector septentrional de la sierra de Hernio ofrece un interesante ejemplo de gestión de un mismo espacio por varios actores en el curso del tiempo, cuyas huellas han quedado registradas, tanto en los archivos locales como en el paisaje. 


\subsection{Fuentes documentales, toponimia y etnografía}

Como comentábamos en la introducción, los seles fueron espacios cuyo uso se normativizó y, en no pocas ocasiones, fue objeto de disputa entre diversos actores sociales. Uno y otro hecho tienen su correspondiente reflejo en las fuentes administrativas y jurídicopolíticas. En nuestro caso de estudio, la documentación obrante en el Archivo Histórico Municipal de Zestoa es una referencia inexcusable. A través de ella, abarcamos el periodo comprendido entre los siglos XIV y XIX, en el que se encuentran numerosas referencias, directas o indirectas, a la existencia y aprovechamiento de los seles. Entre las fuentes documentales no podemos dejar de mencionar, también, el registro de los bienes inmuebles de naturaleza rústica de Gipuzkoa, que nos proporciona información acerca de las delimitaciones actuales de las parcelas, en lo que a la propiedad se refiere, en las que es oportuno comprobar si los seles han dejado su impronta (Fig. 1) (Rementeria \& Quintana, 2013).

Por otra parte, varios trabajos recientes (e.g. Zaldua, 1996, 2006, 2015; Gogeascoechea, Juaristi \& Moro, 2009, 2010, 2011; Arenzana, 2010; Rementeria \& Quintana, 2013) han puesto en evidencia el interés que el análisis de la toponimia tiene para la identificación física de estos espacios. Huelga decir que, a pesar de los pequeños cambios que pueda sufrir a lo largo de las centurias, la denominación de los espacios físicos tiende a perdurar en el tiempo, garantizando así su correcta trazabilidad. De hecho, de los diecisiete seles registrados en las fuentes administrativas y jurídicas, quince (los de Antxiturbi, Etumeta, Ezkurroa, Erdoizta, Artaunsoro, Barrensoro, Galleku, Belaunburu, Komisolatza, Legarralde, Hezurtza, Elkamen Nagusia, Elkamen Txiki, Gazume y Zezenarriaga) mantienen en la actualidad, con algunas modificaciones, su topónimo. En los dos casos restantes, los registros documentales permiten certificar su transformación en el curso de los siglos (de Herniogurutzeaga a Zelatun y de Adaolatza a Sagarain), lo que garantiza la identificación entre los topónimos modernos y los antiguos. Además, los antiguos usos dejaron su impronta en algunos casos: los topónimos con el componente saroi ("sel» en euskera; Zaldua, 2015), Artaunsoro y Barrensoro son dos claros ejemplos de ello; o aquellos que hacen referencia a las actividades desarrolladas en ellos, como los casos de Komisolatza y Adaolatza, que incorporan el componente olatza ("lugar donde hay cabañas", olak). Es decir, a pesar de que, en ocasiones, el uso de estos espacios no deje cicatrices visibles en el paisaje, sí que las deja en la memoria colectiva.

Otro recurso fundamental para conocer la percepción que las sociedades locales han tenido de estos espacios y la relación que han entablado con ellos son las fuentes orales. Tratándose de espacios "periféricos» respecto de las territorialidades de las dos comunidades consideradas, su percepción varía considerablemente de un individuo a otro: 
desde aquellas personas que, por su ocupación, los identifican como un elemento importante de su propia experiencia vital (como los pastores, los carboneros o los habitantes de los caseríos más cercanos) hasta el grueso de la población, que los relaciona esencialmente con el ocio. En cualquier caso, se trata de unos espacios dotados de una fuerte carga simbólica e identitaria, en los que las huellas de diversas prácticas jurisdiccionales y productivas son ampliamente reconocidas y valoradas, aunque actualmente en declive.

Estas fuentes orales de carácter etnográfico se han documentado mediante la realización de entrevistas semiestructuradas con distintos habitantes tanto de Aizarna (localidad incluida en el municipio de Zestoa) como de Errezil. Aunque la mayoría de estas entrevistas se han llevado a cabo de manera individual, en algunos casos se han podido realizar experiencias de conversaciones grupales, que han permitido matizar y enriquecer numerosas cuestiones mediante la confrontación de distintas memorias. Entre las cuestiones abordadas, destacan las siguientes: a) la microtoponimia; b) el valor simbólico otorgado a los distintos espacios productivos de la montaña; c) las formas de delimitación y control de acceso a los recursos agroganaderos y forestales presentes en los antiguos seles; y d) los usos actuales y pasados de estos espacios. Los resultados de estas entrevistas permitieron identificar con precisión una serie de lugares, marcadores y antiguos usos, lo que ofreció una muy alta resolución espacial en el estudio del espacio de montaña de Hernio.

\subsection{El estudio arqueológico del paisaje}

Con anterioridad al inicio de los trabajos de prospección arqueológica extensiva sobre el terreno, se llevaron a cabo las labores de investigación relacionadas con las fuentes documentales. De esta manera, pudo realizarse la identificación toponímica de los seles. Trabajos pretéritos para la vertiente cantábrica del País Vasco (e.g. Gogeascoechea, Juaristi \& Moro, 2009, 2010, 2011; Arenzana, 2010; Rementeria \& Quintana, 2013), habían evidenciado la transmisión de los nombres propios de estos lugares. Este extremo nos facilitaba delimitar previamente el área de prospección, aplicando siempre la cautela de asumir que la toponimia constituye una herramienta meramente orientativa, puesto que la trasmisión de la configuración espacial no es mimética.

El trabajo documental y las fuentes etnográficas también nos permitieron identificar aquellos marcadores, biológicos o antrópicos, que se han venido utilizando en el curso del tiempo para delimitar los distintos usos y aprovechamientos en torno y dentro de los seles (Tabla 1). Este tipo de marcadores suelen pasar desapercibidos y rara vez son identificados e interpretados como el producto de una acción social consciente y planificada. 
Sin embargo, constituyen elementos de gran interés a la hora de identificar diversas prácticas e intensidades de apropiación y explotación de los espacios de montaña, tal y como ha podido documentarse en las investigaciones llevadas a cabo en los Apeninos de Liguria por el Laboratorio di Archeologia e Storia Ambientale de la Universidad de Génova (e. g. Cevasco, 2007; Stagno, 2016, 2017, 2018).

\section{TABLA 1}

Marcadores empleados durante la prospección para la identificación de distintas prácticas y formas de ocupación

\begin{tabular}{|c|c|c|c|}
\hline Tipo de elemento & ráctica social identificada & Forma de apropiación & Cronología \\
\hline Alineación de lajas & División parcelaria & Temporal/permanente & Época moderna \\
\hline Biomarcador: abedul (Betula pendula) & División parcelaria & Temporal/permanente & Indeterminado \\
\hline Biomarcador: endrino (Prunus spinosa) & División parcelaria & Temporal/permanente & Indeterminado \\
\hline Biomarcador: espino albar (Crataegus monogyna) & a) División parcelaria & Temporal/permanente & Indeterminado \\
\hline Biomarcador: fresno (Fraxinus excelsior) & División parcelaria & Temporal/permanente & Indeterminado \\
\hline Biomarcador: haya (Fagus sylvatica) & División parcelaria & Temporal/permanente & Indeterminado \\
\hline Borda (cabaña) & Ganadería, carboneo & Temporal/permanente & Época moderna \\
\hline Calera & Cultivo & Permanente & Época moderna \\
\hline Caserío & Habitación & Permanente & Época moderna \\
\hline Muro de piedra seca & División parcelaria & Permanente & Época moderna \\
\hline Pista & Plantación forestal & Temporal & Época contemporánea \\
\hline Repoblación de coníferas (Pinus radiata) & Plantación forestal & Temporal & Época contemporánea \\
\hline Terraza de cultivo & Cultivo & Permanente & Época moderna \\
\hline Trasmocho: haya (Fagus sylvatica) & Carboneo & Temporal & Época moderna \\
\hline
\end{tabular}

Fuente: prospección.

\section{LOS SELES DE HERNIO: FORMAS DE APROPIACIÓNY GESTIÓN}

Si bien existen indicios que apuntan a un origen anterior (Barrena, 1989), las jurisdicciones de las diferentes comunidades que forman el territorio histórico de Gipuzkoa, así como las formas de gobierno y gestión de sus recursos, se fijaron definitivamente durante la Baja Edad Media (Truchuelo, 1997; Ayerbe, 2019). En el caso de la sierra de Hernio, este proceso culminó a finales del siglo XIV, tras la fundación de la villa de Zestoa sobre una base territorial preexistente (la tierra de Aizarna) en $1383^{4}$, y un posterior deslinde de los términos de esta y de la vecina tierra de Errezil en $1385^{5}$. A lo largo de los cuatro siglos posteriores, ambas comunidades mantuvieron una compleja historia de conflictos,

4. Archivo Municipal de Zestoa (AMZ), s. s.

5. AMZ, B.1.1.2. 
negociaciones y acuerdos acerca de los aprovechamientos del monte, y de manera particular en torno a una serie de seles situados a ambos lados de la línea divisoria entre ambas jurisdicciones.

El Archivo Municipal de Zestoa conserva un interesante corpus documental que confirma la importancia de estos seles como eje de las estrategias de apropiación y gestión de los recursos de montaña por parte de ambas comunidades. A través de estas fuentes documentales, podemos reconstruir la historia de una serie de seles situados en las estribaciones septentrionales de Hernio, a ambos lados de la línea divisoria entre Zestoa y Errezil, cuya propiedad fue compartida por estos dos concejos entre los siglos XV y XVIII.

Los seles citados en los distintos expedientes relacionados con esta historia, un total de diecisiete, se extienden en torno a una línea de cimas que asciende desde el entorno de Etumeta, en el límite jurisdiccional entre ambos concejos, hasta el collado de Zelatun; todos ellos cuentan con una accesibilidad similar desde las localidades de Aizarna, dependiente de la villa de Zestoa, y Errezil, a pesar de que la mayoría de ellos se encuentran enclavados dentro del segundo término municipal (Fig. 3).

La primera noticia de estos seles data de 1452, cuando una sentencia arbitral, dictada por vecinos elegidos por ambos concejos para dirimir su modo de aprovechamiento, estableció la prohibición de enajenar estos espacios ${ }^{6}$. En esta sentencia aparecen citados diecisiete seles, divididos en dos grupos en función de su tamaño: los de Antxiturbi, Barrensoro, Erdoizta, Ezkurroa y, quizá, Artaunsoro medían doce coderas, mientras que los de Adaolatza, Galleku, Belaunburu, Elkamen, Etumeta, Gazume, Herniogurutzeaga, Hezurtza, Komisolatza, Legarralde y Zezenarriaga medían solo seis (Fig. 3). Estas coderas eran, al parecer, una unidad radial, equivalente a los gorabilak que se citan en otras comarcas (Díaz de Durana, 1998; Zaldua, 2006). Tal división parece indicar una organización estacional de los pastos, según la cual los seles del primer grupo, de mayor tamaño y situados a cotas más bajas, se dedicarían al pasto del ganado en invierno, mientras que los del segundo, más pequeños y a mayor altura, además de dos veces más numerosos, tendrían, por evidentes motivos topoclimáticos, un uso estival.

Esta sentencia arbitral de 1452 permite inferir algunos aspectos importantes de las prácticas de gestión de los recursos que se llevaban a cabo en estos espacios, así como de la fisionomía del paisaje asociado a tales prácticas. Estos seles eran eminentemente lugares de pasto en los que se permitía al ganado de ambas jurisdicciones «pazcan las yeruas e beuan las agoas e aluergen e tengan sus bustos y actos de vacas", y se prohibía la entrada

6. AMZ, C.5.II.2.2. 
de ganado foráneo ${ }^{7}$. Se trataba, sobre todo, de pastos arbolados, en los que los aprovechamientos forestales se encontraban bastante limitados. El texto de la sentencia dedica un espacio considerable a la protección de los árboles, y en especial de los robles; se permitía el aprovisionamiento de madera para la construcción y mantenimiento de jaolas para el ganado (es decir, cercados) y de cabañas para los vaquerizos, pero se ordenaba «que non corten arboles algunos en los dicho seles a derredor de las dichas jaolas e cabannas en aquellos lugares donde los bustos se aluergan y las vacas se acogen y acuestan, de manera que danno no pueda seguir a las dichas vacas en su albergo». La única excepción era el sel de Elkamen, donde se permitía a los vecinos de Errezil aprovisionarse de madera. Además, los árboles plantados en el interior de los seles se considerarían "commo si ellos mismos nasçiesen y se criasen sin plantío", es decir, comunes a ambos concejos y, por tanto, protegidos de la misma manera que los árboles silvestres. Esta prohibición de talar árboles en el interior de los seles se vería confirmada poco después en las ordenanzas municipales de Zestoa, promulgadas en $1483^{8}$.

\section{FIGURA 3}

\section{Localización de los seles comunes de los concejos de Zestoa y Errezil en Hernio}
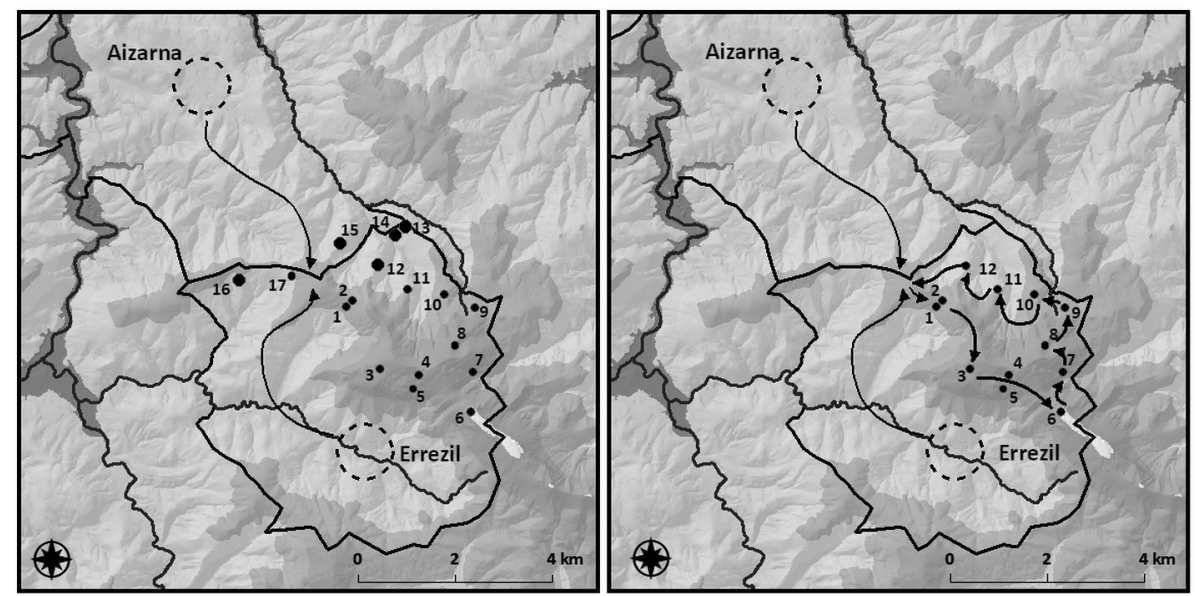

Nota: (1) Legarralde; (2) Komisolatza; (3) Hezurtza; (4) Elkamen Nagusia; (5) Elkamen Txiki; (6) Herniogurutzeaga/Zelatun; (7) Zezenarriaga; (8) Gazume; (9) Adaolatza/Sagarain; (10) Belaunburu; (11) Galleku; (12) Erdoizta; (13) Artaunsoro; (14) Barrensoro; (15) Ezkurroa; (16) Antxiturbi; (17) Etumeta. (izq.) sentencia arbitral de 1452, distinguiendo entre seles de 6 coderas (1-11) y 12 coderas (12-16) (dcha.). Revisiones realizadas entre 1512 y 1788, con indicación del orden habitual de visita.

Fuente: elaboración propia a partir de la base cartográfica del Centro Nacional de Información Geográfica.

7. Ibid.

8. GARCía FERnÁNDEZ (1997: arts. 53, 54 y 55). 
Pero la presencia de robles en estos espacios, más allá de evitar que se perturbase el sueño del ganado y de proveer madera para los vecinos, cumplía una función fundamental en el mantenimiento del agroecosistema forestal de Hernio, ya que su fruto resultaba, en este periodo, imprescindible para asegurar el pasto del ganado porcino. Así, la sentencia de 1452 estipulaba lo siguiente:

\begin{abstract}
"[...] al tiempo que en los dichos seles [...] obiere pasto de bellotta y en otro pasto qualquier para engordar puercos [cada uno de los dos concejos nombrara dos representantes para realizar conjuntamente una estimación del] pasto de quantos puercos entienden y creen que lo es y puede ser en los dichos seles e en cada vno d'ellos. E assí, según su examinaçión e declaraçión, que ayan a medias los dichos conçejo e vniuerssidad el dicho pasto de los dichos seles [...], e que meta tantos de puercos el dicho conçejo e tierra de Ayçarna como la dicha uniuerssidad de Rexil» ${ }^{9}$.
\end{abstract}

A lo largo de los cuatro siglos que siguen a esta sentencia, los representantes de ambos concejos realizarán conjuntamente una serie de visitas periódicas para inspeccionar la situación de estos seles y renovar el pacto de posesión compartida sobre ellos; hecho que parece reflejar cierta conflictividad y que habría hecho precisa una revisión regular con el fin de encauzarla.

El primer acto del que hay constancia en este sentido es una revisión llevada a cabo en $1512^{10}$. De los diecisiete seles citados en la sentencia de 1452, esta revisión menciona ya solo doce: Legarralde, Komisolatza, Hezurtza, Elkamen (ahora subdividido en dos seles, Elkamen Nagusia, o «mayor» y Elkamen Txikia, o «menor»), Herniogurutzeaga, Zezenarriaga, Gazume, Adaolatza, Belaunburu, Galleku y Erdoizta, que se visitaban siguiendo un recorrido circular que partía del lugar de Etumeta (Fig. 3, dcha.).

Revisiones similares de los mismos doce seles se llevarán a cabo en 1531, 1547, 1595, 1613 , y $1730^{11}$, con el objetivo de comprobar el estado del arbolado y renovar, en caso de necesidad, la austerreyça $a^{12}$ o los mojones perimetrales. Tampoco son extrañas las menciones a otros signos liminales: en el sel de Erdoizta, por ejemplo, la revisión de 1512 indica que la austerreyça se encontraba acompañada de un biomarcador, concretamente por

9. AMZ, C.5.II.2.2.

10. AMZ, C.5.I.1.5.

11. AMZ, C.5.I.2.3.

12. Piedra cenizal que solía colocarse en el centro del sel. Véanse ZaLduA (2006, 2015), y REMENTERIA y QUINTANA (2013). 
«un espino e árvol llamado arançavalça», es decir, un endrino (Prunus spinosa); este tipo de biomarcadores podían constituir una garantía contra el riesgo de que los mojones fueran movidos con intenciones poco honestas, como de hecho sucedía en ocasiones ${ }^{13}$.

La recurrente revisión y mantenimiento de los seles y sus límites revela la importancia que estos espacios tenían en el marco de las economías locales, pero puede también reflejar las tensiones derivadas de determinadas circunstancias coyunturales. De hecho, no puede sorprender que los conflictos originados en torno a su gestión se documenten desde el siglo $\mathrm{XVI}^{14}$, un periodo de cambios significativos en la gestión de la ganadería y de los recursos forestales a escala regional (Aragón, 2001).

Como hemos visto, la propiedad compartida de estos seles se basaba, desde finales de la Edad Media, en un aprovechamiento ganadero, que implicaba, a nuestro juicio, un uso estacional de los distintos espacios en función de sus características topográficas y, en particular, de su altitud. Este modelo de ganadería trasterminante, implantado a escala local, se ha documentado en numerosas localidades vascas. Sin embargo, parece que su peso relativo fue disminuyendo a lo largo de la época moderna, progresivamente sustituido por un sistema de trashumancia de larga distancia, basado principalmente en el ganado ovino; una transición que se reflejaría en una reorganización normativa a escala regional (Aragón, 2009).

13. En 1538, los vecinos de Zestoa acusaron a los de la vecina localidad de Aia de haber usurpado su propiedad, moviéndoles los mojones del sel de Adaolatza (hoy Sagarain) para reducir su radio. Aunque los aludidos respondieron negando la mayor, el Concejo de Zestoa efectuó públicamente un nuevo amojonamiento en este sel, reclamando su derecho a albergar ganados, tener sus cabañas y cortar montes y venderlos, y disponer de todos los aprovechamientos del sel pro indiviso con el Concejo de Errezil. Véase AMZ, C.5.I.1.6.

14. Se trata, fundamentalmente, de controversias relacionadas con el aprovechamiento de los recursos presentes en estos espacios, tal y como muestran, entre otros ejemplos, la querella criminal impulsada por el Concejo de Zestoa en 1538 contra ciertos particulares que habían cortado hayas y robles en los doce seles comunes (AMZ, E.7.II.17.12); la rápida intervención de los jurados de Zestoa en 1547 contra Juan de Arzallus, quien, «en un mendisoro [literalmente, "campo de cultivo en el monte"] que tenía fecho y sembrado de mijo, en el terminado de Régil, cerca del sel de Legarralde [...], havía metido el seto del dicho mendisoro en el dicho sel» (AMZ, C.5.I.1.8); o el convenio firmado por los concejos de Zestoa y Errezil en ese mismo año, después de que este último vendiera "por error» 110 cargas de carbón en rama del sel de Galleku, que hubo de compensar cediendo al de Zestoa una cantidad equivalente en los demás seles comunes (AMZ, C.5.II.2.2). En ocasiones, las disputas también podían originarse por motivos relacionados con los actos de significación jurisdiccional, como la queja realizada por los apoderados de Errezil en 1613 porque los jurados de Zestoa realizaran la revisión de los seles comunes enarbolando su vara de mando, acción que podía entrañar, por la vía de los hechos, una implícita reivindicación jurisdiccional sobre los espacios adyacentes situados en los términos de Errezil (ibid.). 
Este proceso pudo implicar un cambio significativo en la presión ganadera ejercida sobre la sierra de Hernio, con un refuerzo progresivo de otros aprovechamientos -como los agrarios o los forestales, como hemos visto- hasta el punto de vaciar de función la propiedad compartida de estos espacios o, al menos, cuestionar su economía de escala en un contexto con distintas prioridades de explotación. Así, tras varios años de desencuentros entre los representantes de ambos concejos, un acuerdo firmado en 1788 declara que, ante la «duda y controversia» suscitada en torno al lugar «donde se han de vender en almoneda la leña de los referidos seles comunes [...] sería muy ventajoso [...] que se dividan y partan dichos doze seles» para que cada concejo obtuviera la gestión privativa de su parte. La mitad de cada sel que habría de corresponder a cada parte se decidió mediante sorteo, y la partición se ejecutó en octubre de ese mismo año mediante un nuevo amojonamiento ${ }^{15}$.

Pero la nueva situación tampoco habría de durar, puesto que el ciclo bélico y la posterior oleada liberalizadora que marcaron el fin del siglo XVIII y el principio del XIX dejaron totalmente desarticuladas las economías rurales basadas en la gestión colectiva del comunal. En Gipuzkoa, tal y como consta en un expediente elaborado en 1814 por orden de las Juntas Generales del territorio, la enajenación de bienes municipales fue un fenómeno extendido después de 1764, y sobre todo tras una facultad real emitida a tal fin en $1808^{16}$. Este expediente recoge los informes emitidos por cada uno de los municipios guipuzcoanos para responder a la citada orden. En los casos de Zestoa y Errezil, tales informes recogen la venta de numerosos bienes, que incluían casas y terrenos situados en los seles aquí estudiados, que fueron totalmente privatizados. La historia del monte compartido entre ambas comunidades llegó así a su fin con la llegada del régimen liberal.

\section{PAISAJE Y PRÁCTICAS SOCIALES}

$\mathrm{El}$ análisis combinado de las fuentes documentales, orales y toponímicas, por un lado, y la prospección realizada sobre el terreno, por otro, permiten identificar en el paisaje actual las trazas de diversas prácticas sociales desarrolladas en estos espacios (Tabla 2) y reconstruir su historia. El estudio de estas prácticas resulta de gran interés a la hora de observar cómo, a lo largo del tiempo, los seles de la sierra de Hernio han conocido diversos cambios en las formas de gestión y explotación de los recursos presentes en el medio, así como la antropización de los ecosistemas, que tienen relación con las formas de apro-

15. AMZ, C.5.II.2.2; C.5.I.3.4.

16. Archivo General de Gipuzkoa (AGG), JD IM, 1/17/80. 
piación analizadas más arriba y se reflejan, a su vez, en determinados elementos presentes en el paisaje aún en la actualidad.

TABLA 2

Inventario arqueológico de los marcadores identificados durante las labores de prospección arqueológica

\begin{tabular}{|c|c|c|c|}
\hline $\begin{array}{l}\text { Tipo de } \\
\text { elemento }\end{array}$ & $\begin{array}{l}\text { Unidad de paisaje } \\
1300-500 \text { m s. } n . m .\end{array}$ & $\begin{array}{l}\text { Unidad de paisaje } \\
2500-800 \text { m s. } n . m .\end{array}$ & $\begin{array}{l}\text { Unidad de paisaje } \\
3>800 \mathrm{~m} \mathrm{~s} . \mathrm{n} . \mathrm{m} .\end{array}$ \\
\hline Alineación de lajas & - & - & 1 \\
\hline Biomarcador: abedul (Betula pendula) & - & 4 & - \\
\hline Biomarcador: endrino (Prunus spinosa) & - & - & - \\
\hline Biomarcador: espino albar (Crataegus monogyna) & - & 1 & - \\
\hline Biomarcador: fresno (Fraxinus excelsior) & - & 4 & 2 \\
\hline Biomarcador: haya (Fagus sylvatica) & 1 & 2 & 3 \\
\hline Borda (cabaña) & 7 & 22 & 15 \\
\hline Calera & 2 & - & - \\
\hline Caserío & 20 & 3 & - \\
\hline Muro de piedra seca & 7 & 24 & 44 \\
\hline Pista & 1 & - & 1 \\
\hline Repoblación de coníferas (Pinus radiata) & 52 & 40 & 9 \\
\hline Terraza de cultivo & 5 & 1 & 2 \\
\hline Trasmocho: haya (Fagus sylvatica) & - & 15 & 6 \\
\hline Otros & 9 & 21 & 26 \\
\hline
\end{tabular}

Fuente: prospección.

Atendiendo a las evidencias de las diferentes prácticas desarrolladas en los seles, estos pueden agruparse en tres grandes conjuntos (Fig. 4):

a) El primer conjunto abarca los seles documentados en época bajomedieval como invernizos, transformados después en caseríos; todos ellos se encuentran situados en la parte baja de la sierra, en altitudes que oscilan entre 300 y $500 \mathrm{~m}$ s. n. m.

b) El segundo conjunto abarca los seles situados en la zona media de la sierra (500$800 \mathrm{~m} \mathrm{s.} \mathrm{n.} \mathrm{m.),} \mathrm{un} \mathrm{espacio} \mathrm{actualmente} \mathrm{ocupado} \mathrm{por} \mathrm{pastos} \mathrm{y} \mathrm{bosques} \mathrm{degra-}$ dados en el que los usos tradicionales han desaparecido casi completamente.

c) Finalmente, el tercer conjunto, situado por encima de los $800 \mathrm{~m} \mathrm{s.} \mathrm{n.} \mathrm{m.,} \mathrm{se}$ compone de los seles que han mantenido una función pastoral hasta la actualidad. 
Tal y como se desgranará a continuación, cada uno de estos conjuntos puede agruparse en otras tantas unidades de paisaje, definidas por unas características comunes que revelan la existencia de unas pautas específicas de evolución histórica.

\section{FIGURA 4}

\section{Unidades de paisaje identificadas en la sierra de Hernio} y distribución de los seles en ellas

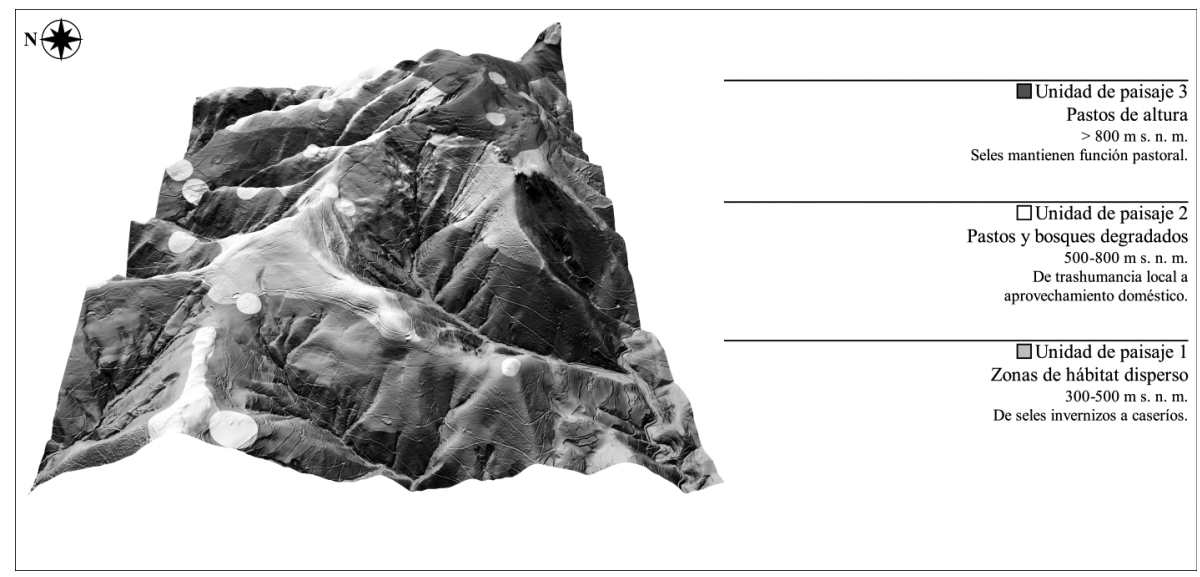

Fuente: elaboración propia a partir de la base cartográfica del Centro Nacional de Información Geográfica.

\subsection{Unidad 1: Zonas de hábitat disperso}

La primera unidad de paisaje que puede distinguirse en el espacio estudiado engloba los seles situados en las zonas más bajas al norte de la sierra de Hernio, en la actualidad transformados en un espacio de hábitat disperso donde las repoblaciones forestales se alternan con caseríos más o menos aislados; en torno a estos últimos, terrazas, caleras, subparcelaciones y muros de piedra seca indican un acondicionamiento intensivo del medio físico con fines agrarios (Fig. 5a). La mayor parte de los caseríos situados en esta área no datan del periodo medieval, cuando parece haberse formado la base del poblamiento rural actual ${ }^{17}$, sino que aparecen documentados en dicho periodo como seles, algunos pertenecientes como propios a la villa de Zestoa ${ }^{18}$ y otros incluidos en la lista de seles po-

17. Para el caso de Zestoa, contamos con un apeo realizado en 1479 (AMZ, C.I.1.5.4) y un censo de 1542 (AMZ, B.I.1.9.1). Ambos documentos realizan una revisión sistemática de los espacios de habitación y cultivo de la jurisdicción de Zestoa, sin mencionar en ningún caso el entorno que nos ocupa; en los siglos XV-XVI, el poblamiento parece haberse circunscrito al valle del Urola y a las cuencas de Akoa y Aizarna, con solo algunas casas dispuestas en las laderas más bajas de las montañas circundantes. 
seídos proindiviso por esta y la universidad de Errezil. Se trata, en casi todos los casos, de seles incluidos en el grupo de los invernizos, situados por debajo de los $500 \mathrm{~m} \mathrm{s.} \mathrm{n.} \mathrm{m.}$

\section{FIGURA 5}

\section{Zonas de hábitat disperso}
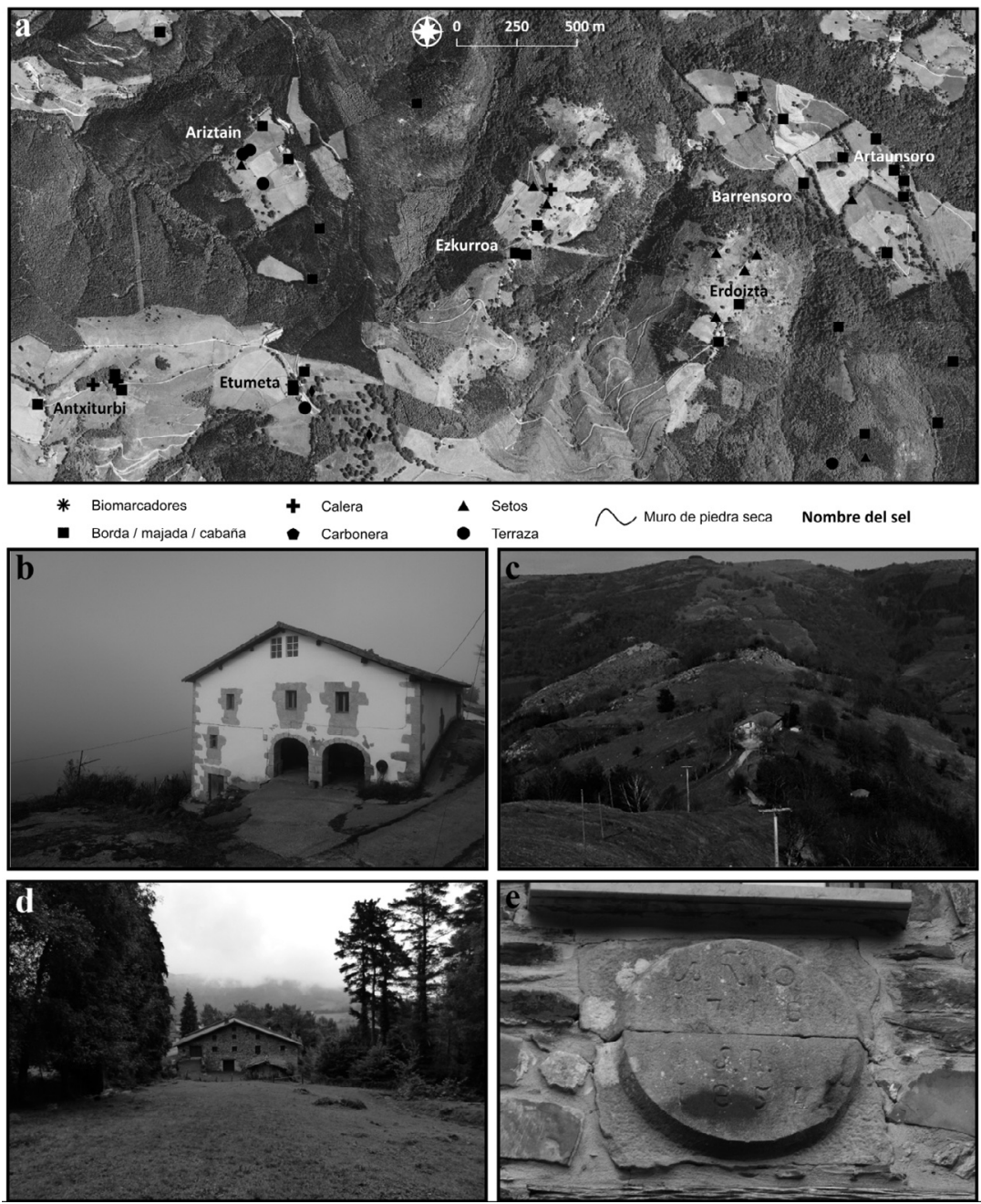

Nota: (a) planimetría de detalle de los seles comprendidos en esta unidad; (b) venta de Etumeta en el lugar del antiguo sel; (c) caserío Ezkurroa; (d) caserío Erdoizta; (e) inscripción epigráfica en la fachada del caserío Erdoizta.

Fuente: fotografías de Josu Narbarte.

18. Por ejemplo, las ordenanzas municipales de 1483 citan los seles de Ariztain, Ilurdan y Otola como propios del Concejo de Zestoa (GARCÍA FERNÁNDEZ, 1997); los tres son actualmente caseríos. 
Existen bastantes evidencias documentales de la conversión de estos seles en caseríos a lo largo de la época moderna. Ya la sentencia arbitral de 1452 refiere la existencia de cultivos temporales en uno de los diecisiete seles que menciona. Se trata, concretamente, del sel de Artaunsoro, del cual se dice que el Concejo de Errezil había vendido su correspondiente mitad $-\mathrm{O}$, mejor dicho, el usufructo de esta- a un particular, y que algunas partes de dicho sel se hallaban cultivadas por otro vecino de la misma universidad en régimen de prestación ${ }^{19}$. Tanto este sel como el vecino de Barrensoro fueron vendidos por el Concejo de Zestoa a Juan Pérez de Idiáquez en 1503 y, para 1562, ambos aparecen transformados en caseríos e incorporados al vínculo del linaje nobiliario de los Zarautz junto con otra serie de bienes situados en el entorno (Aragón, 2015).

De hecho, tanto estos seles como los de Antxiturbi, Etumeta y Ezkurroa se hallan ausentes en la revisión realizada por los jurados de Zestoa y Errezil en una fecha tan temprana como $1512^{20}$. Desconocemos la fecha exacta de construcción de los caseríos Antxiturbigoikoa y Antxiturbibehekoa, erigidos en el antiguo sel de Antxiturbi, así como el proceso que condujo a su enajenación, aunque el paso de un uso ganadero a uno agrario debió producirse entre 1452 y 1512. En el caso de Etumeta, la revisión de 1512 ya no lo incluye en la lista de seles, pero menciona el topónimo sin referir la existencia de habitación alguna. Aunque en este lugar existió una venta desde, al menos, mediados del siglo XVI (Achón, 1998), el caserío homónimo solo aparece citado desde 1613, cuando se lo menciona como perteneciente al Concejo de Errezil ${ }^{21}$. En la actualidad, el núcleo de Etumeta está formado por tres caseríos, además de la propia venta (Fig. $5 b)$.

El caso de Ezkurroa, por su parte, es uno de los mejor documentados, puesto que el Libro de Ayuntamiento de Zestoa recoge un acta del 24 de febrero de 1636 en la que, ante la demanda de algunos vecinos de construir nuevos caseríos y cultivar las tierras, se promueve la construcción de una nueva casa en dicho paraje:

"Asi bien decretaron que, a tanto se tiene notiçia que hay en la dicha villa personas que quieren edificar y labrar casas y caserías en jurisdicción de esta dicha villa, pagándose la renta [...] se les permita de açerlas en quoalquier monte de la jurisdicción de esta dicha villa y para ello se les dé de graçia el maderamen neçesario [...] Y luego [...] el dicho Dm de Arreche [alcalde ordinario de la villa] ofreció de açer y edificar una cassa en el puesto llamado Ezcurrua dentro de qua-

19. AMZ, C.5.II.2.2.

20. AMZ, C.5.I.1.5.

21. AMZ, C.5.II.2.2. 
tro años, con la misma calidad y con que se le dé para la dicha cassa un pedaço de castañal de lo que está en el dicho puesto» ${ }^{22}$.

El Concejo de Errezil impugnó la decisión alegando tener derechos sobre el terreno, arguyendo, además, el perjuicio que la nueva construcción supondría para los moradores de la cercana casa de Etumeta ${ }^{23}$. El corregidor de Gipuzkoa resolvió el pleito en 1655, autorizando la construcción del nuevo caserío (Fig. 5c) y su arrendamiento a un particular $^{24}$. Las rentas de él provenientes aparecen en los libros de cuentas municipales al menos desde $1712^{25}$, y fue vendido por el Concejo a principios del siglo XIx, junto con muchos otros bienes propios de la villa, según consta en el inventario de bienes enajenados por el Municipio de Zestoa tras la guerra de la Convención ${ }^{26}$.

El caso de Erdoizta es singular. De los seles citados en 1452, es el único sel invernizo que sigue formando parte del conjunto de seles comunes después de 1512; en las sucesivas revisiones, además, se subraya explícitamente que este es el único del grupo que mide doce coderas, el doble que los demás ${ }^{27}$. En la actualidad, el caserío homónimo luce en su fachada una inscripción epigráfica con el texto "AÑO 1715/1851», probablemente las fechas de construcción y reconstrucción o reforma (Fig. $5 \mathrm{~d}$ ), coincidentes con las primeras menciones documentales al caserío ${ }^{28}$. Erdoizta forma hoy un minúsculo núcleo rural que incluye dos caseríos, además de una escuela, activa a principios del siglo xx, y una ermita dedicada a san Isidro, lo cual da idea del desarrollo y actividad que llegaron a tener estos asentamientos dispersos de nueva planta a finales de la época moderna.

El paso de un uso ganadero a otro agrario en estos espacios se operó, por tanto, en un amplio lapso temporal, que va del siglo XVI al XVIII, cuando familias campesinas edificaron y ocuparon, con la anuencia e incluso el impulso de los respectivos concejos, unos caseríos caracterizados por su gran dispersión y aislamiento respecto de los núcleos de población de la comarca. Así, cuando en 1743 y 1773 se realicen las revisiones de los lí-

22. AMZ, A.1.3, 24 de febrero de 1636.

23. Archivo de la Real Chancillería de Valladolid (ARCV), C.3134.1.667.

24. AMZ, E.II.18.7.

25. AMZ, C.2.1.

26. AGG, JD IM 1.17.80.

27. AMZ, C.5.II.2.2

28. Ningún caserío aparece citado en la revisión de los doce seles realizada en 1730 (AMZ, C.5.II.2.2), aunque sí en los apeos de límites jurisdiccionales entre Zestoa y Errezil de 1743 y 1773 (AMZ, C.5.I.2.15; C.5.I.2.17; C.5.I.2.19). La casa de Erdoizta también aparece explícitamente mencionada en el acta de división de los doce seles firmada en 1788, donde se especifica que el sel se dividió «de la casa a la peña, en línea recta» (AMZ, C.5.II.2.2). 
mites jurisdiccionales entre Zestoa y Errezil, las casas de Etumeta, Ezkurroa o Erdoizta serán referencias espaciales fundamentales a la hora de definir la localización de los distintos mojones ${ }^{29}$. Este hecho refleja, por tanto, un proceso de expansión del espacio cultivado a costa del monte a lo largo de la época moderna, posiblemente asociado con la introducción de cultivos americanos como el maíz y a una cierta desarticulación de las formas de acción social de base comunitaria que habían regido hasta entonces (e.g. Bilbao \& Fernández de Pinedo, 1984; Aragón, 2015).

En otras zonas del País Vasco se ha documentado igualmente la formación, a lo largo de la época moderna, de comunidades de montaña basadas en un poblamiento fuertemente fragmentado y disperso, localizado sobre antiguas zonas de pastos o bosques, que desarrollan una economía de carácter mixto combinando actividades agrarias y ganaderas a escala doméstica con ocupaciones ocasionales o estacionales relacionadas con el aprovechamiento de los recursos de montaña (Barandiaran, 1961; Arvizu, 1992; Amo \& Narbarte, 2018). Se trata de comunidades situadas en la periferia de los respectivos marcos territoriales en los que se insertan, que no suelen contar con una identidad colectiva formalizada y mucho menos una institucionalización política; sin embargo, esta constatación no debe camuflar la existencia de redes informales, pero estables, basadas en la vecindad y que se reflejan en diversas formas de cooperación y coordinación para la gestión de los recursos (e.g. Echegaray, 1933).

Aunque la mayor parte de estos caseríos se encuentran deshabitados en la actualidad, toda la zona aparece intensamente cultivada en las fotografías aéreas de 1945-1946 y 1956-1957. El abandono de la actividad agraria sucedió, según fuentes orales, entre las décadas de 1960 y 1980, si bien estos espacios siguen siendo usados de manera extensiva como zonas de pasto, praderas y alguna huerta.

\subsection{Unidad 2: Pastos y bosques degradados}

La segunda unidad de paisaje que puede discernirse en la sierra de Hernio se corresponde con los seles de Legarralde, Komisolatza, Galleku, y Belaunburu. Se trata de un conjunto de seles que nunca fueron transformados en caseríos, y solo ocasionalmente parecen haber albergado habitaciones o cultivos, aunque temporales. Tras aparecer citados en todos los actos de revisión conjunta que tuvieron lugar entre los siglos XVI y XVIII, estos espacios fueron enajenados de manera generalizada, junto con la mayor parte de los espacios forestales y ganaderos circundantes, a comienzos del xIx; así lo refleja el informe de la uni-

29. AMZ, C.5.I.2.15; C.5.I.2.17; C.5.I.2.19. 
versidad de Errezil sobre bienes propios vendidos tras la guerra de la Convención ${ }^{30}$. Los compradores fueron, en la mayoría de los casos, vecinos de las dos comunidades afectadas, que probablemente ya explotaban los recursos locales con anterioridad; de modo que el cambio de titularidad no debió necesariamente entrañar cambios en las prácticas desarrolladas en estos espacios. Una vez desarticulada la trashumancia local documentada en los siglos XV y XVI, las prácticas desarrolladas en estos espacios consistieron fundamentalmente en el pasto extensivo de ganado doméstico, carboneo y aprovisionamiento de materias primas como la leña, el helecho o el árgoma necesarios para la producción de estiércol. A partir del siglo XIX, estos aprovechamientos domésticos serán a su vez sustituidos por la plantación de especies de rápido crecimiento, orientadas a satisfacer las demandas de una creciente industria papelera; uso que llegará a convertirse, a lo largo del siglo $\mathrm{xx}$, en la principal fuente de ingresos del campesinado en toda la vertiente cantábrica del País Vasco (Michel, 2006; Michel \& Gil Sánchez, 2013).

En la actualidad, los entornos de Komisolatza, Sagarain y, sobre todo, Belaunburu, presentan una cobertura vegetal compuesta por pastos abandonados, zarzales, argomales y helechales. En Galleku y Legarralde, por su parte, predominan las repoblaciones forestales, principalmente de Pinus radiata (Fig. 6a). Se trata de áreas caracterizadas por fuertes pendientes, en las que las trazas de antiguos aprovechamientos generalmente presentan una visibilidad muy escasa debido a la intensiva explotación forestal de que son o han sido objeto, basada en un modelo de monocultivo de rápido crecimiento. Esta explotación forestal intensiva implica la apertura regular de pistas y la entrada de maquinaria pesada, la deforestación regular de amplias superficies de terreno, y los problemas de erosión que ello conlleva (Fig. 6b).

A pesar de estos problemas de conservación, el concurso de diversas evidencias nos permite identificar todos los seles citados por las fuentes documentales, cuya dedicación ganadera se sostuvo hasta fechas relativamente recientes. Así, a la transmisión toponímica observada en la unidad anterior, se le une la "clásica» morfología circular, visible en el parcelario y, en ocasiones, delimitada por recintos antrópicos; también la existencia de biomarcadores (ejemplares de determinadas especies que presentan manejos específicos como la poda y el trasmocho, cuya presencia difícilmente encontraría otra función diferente a la liminar) y la conservación de bordas, un tipo de estructura estrechamente asociada a la actividad ganadera.

30. AGG, JD IM 1.17.80. 


\section{FIGURA 6}

Pastos y bosques degradados
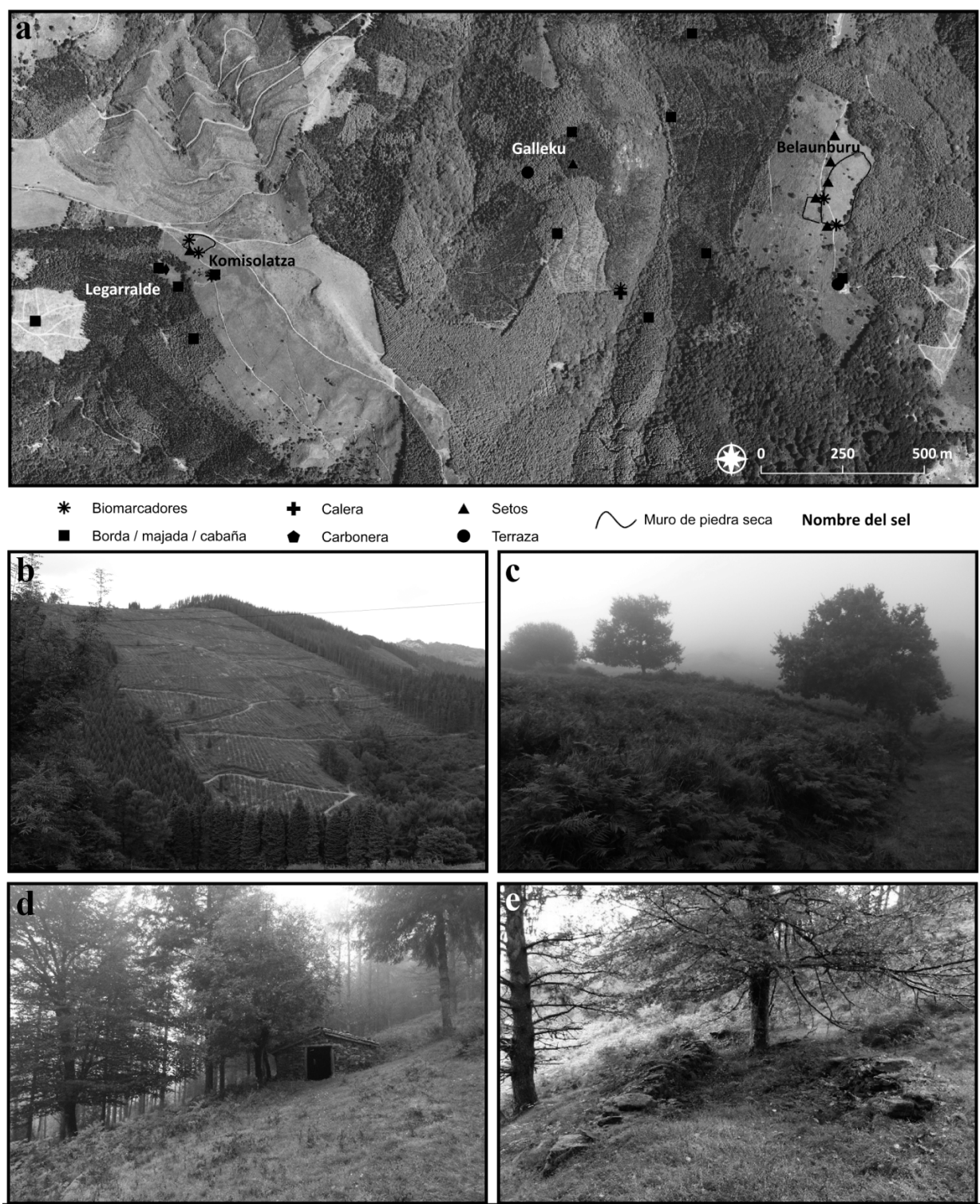

Nota: (a) planimetría de detalle de los seles comprendidos en esta unidad; (b) repoblación de coníferas recientemente taladas junto al sel de Legarralde; (c) cercado circular de piedra seca reforzado con biomarcadores (hayas trasmochas y endrinos) en el sel de Komisolatza; (d) borda rodeada de repoblación forestal en el sel de Legarralde; (e) restos de otra borda abandonada en el sel de Legarralde.

Fuente: fotografias de Josu Narbarte. 
En Komisolatza, las trazas del antiguo sel (véase el Apartado 3) se han conservado bajo la forma de una borda y de un cercado de piedra seca de forma vagamente circular, reforzado con biomarcadores como hayas y endrinos (Figs. 6a y 6c); este último árbol aparece citado como un biomarcador habitual en los seles de Hernio desde al menos $1512^{31}$, lo que sugiere una cierta recurrencia en las prácticas de fijación de los límites en este recinto. El cercano sel de Legarralde también conserva dos bordas, una de ella en ruinas y fuertemente degradada, mientras que la segunda es nueva o se ha renovado recientemente (Figs. 6d y 6e). Entre ambas estructuras, se conservan algunas hayas trasmochas, dispersas entre las repoblaciones de coníferas. En Belaunburu, por el contrario, no se ha podido identificar ninguna borda, aunque sí se conservan varios muros de piedra formando cercados de distintos tamaños y formas, los cuales pueden relacionarse con actividades ganaderas sostenidas en el tiempo. Algunos de estos muros aparecen reforzados por biomarcadores como endrinos y abedules. Finalmente, Galleku constituye un caso singular, ya que se conservan las ruinas de una estructura que podría corresponder a una habitación, posiblemente relacionada con una actividad ganadera o forestal. Junto a esta estructura se conservan los restos de una calera y, ladera arriba, los restos muy erosionados de una borda. En este último caso, el parcelario conserva una forma pseudocircular, probable relicto del antiguo sel.

\subsection{Unidad 3: Pastos de altura}

La tercera unidad de paisaje está formada por pastos de altura situados entre el collado de Zelatun y las cimas de Hernio y Gazume. Este espacio presenta unas características muy definidas: sus cotas, situadas por encima de $\operatorname{los} 700 \mathrm{~m} \mathrm{s.} \mathrm{n.} \mathrm{m.,} \mathrm{y} \mathrm{una} \mathrm{topografía} \mathrm{muy}$ accidentada, dificultan la accesibilidad y acentúan el impacto de los procesos erosivos.

A las evidencias que concurren en la unidad 2, y que nos permiten identificar los seles, en la unidad 3 se suma la "herencia» morfológica de estos en los límites actuales de las parcelas (Figs. 8a y 8c). Esta pervivencia bien pudiera estar relacionada con una menor presión para su gestión privativa derivada de las limitaciones productivas. Podría argüirse que la morfología circular actual se encuentra determinada por su función de redil del presente o pasado inmediato y, por lo tanto, no nos encontraríamos ante los mismos seles de finales de la Edad Media, cuya configuración habría perdurado hasta nuestros días. Un argumento a nuestro juicio determinante contra esta interpretación resulta su dimensión. Recordemos que los seles estivales tenían una dimensión de seis coderas, unidad de medida de 13,6 m relativa al radio de la circunferencia (Díaz de Durana, 2001).

31. AMZ, C.5.I.1.5. 
Pues bien, en aquellos casos en los que la morfología circular o semicircular pervive en el parcelario (como Hezurtza o Galleku), la dimensión del radio de su circunferencia se aproxima mucho a los $81,6 \mathrm{~m}$ que equivaldrían a seis coderas (Figs. 8 a y 8 b).

Los seles localizados en este sector de la montaña son seis, todos ellos estivales: Elkamen Nagusia, Elkamen Txikia, Gazume, Herniogurutzeaga/Zelatun, Zezenarriaga, Hezurtza y Adaolatza/Sagarain. Todos aparecen mencionados desde la sentencia arbitral de $1452^{32}$, con la única excepción de Elkamen Txikia que lo hace en $1512^{33}$. A partir de ese momento, los siete seles aparecen regularmente citados en todas las revisiones hasta el siglo XVIII. La privatización de estos seles parece haberse dado, junto con el grueso de los bienes municipales de Errezil, a principios del siglo XIX, según consta en el expediente de ventas de bienes públicos realizadas entre 1764 y $1814^{34}$. Ahora bien, a pesar de estas enajenaciones, los antiguos seles han dejado su huella en la morfología de los parcelarios (Fig. 8), en contraste con otras zonas de la sierra de Hernio, donde la privatización supuso la creación de lotes paralelos de similares dimensiones.

En esta unidad de paisaje se conservan numerosos elementos ligados al pastoreo: bordas, cercados de piedra seca y biomarcadores liminares, como hayas trasmochas, espinos albares y endrinos (Fig. 7a). Destacan conjuntos bien definidos como el sel de Hezurtza, delimitado por un muro de piedra seca y subdividido en dos zonas con una borda anexa (Figs. 7a, 7b y 7c). Probablemente, no nos encontremos ante una subdivisión del antiguo sel, sino ante el resultado de un añadido posterior a su privatización, siendo el recinto primigenio el delimitado por los biomarcadores (Fig. 8a).

El sel de Elkamen Nagusia es un gran recinto circular asociado a una borda y delimitado por muros de piedra seca, alineaciones de lajas (subdivisión de carácter meramente funcional) y biomarcadores como endrinos (Prunus spinosa) y fresnos (Fraxinus excelsior). El topónimo de Elkamen Txikia no ha podido ser ubicado con total exactitud, aunque podría corresponderse con alguno de los varios recintos y bordas situados al sur de Elkamen Nagusia. En el caso de Zezenarriaga, tanto los cercados como el espacio central del sel aparecen señalizados por fresnos trasmochados, con algunas bordas aún en uso (Fig. 7a). Finalmente, tanto en Gazume como en Zelatun (antiguo sel de Herniogurutzeaga) se constata la existencia de muros de piedra seca formando cercados de gran tamaño, cuya forma ortogonal hace pensar en una reorganización reciente.

32. AMZ, C.5.II.2.2.

33. AMZ, C.5.I.1.5.

34. AGG, JD IM 1.17.80. 


\section{FIGURA 7}

\section{Pastos de altura}
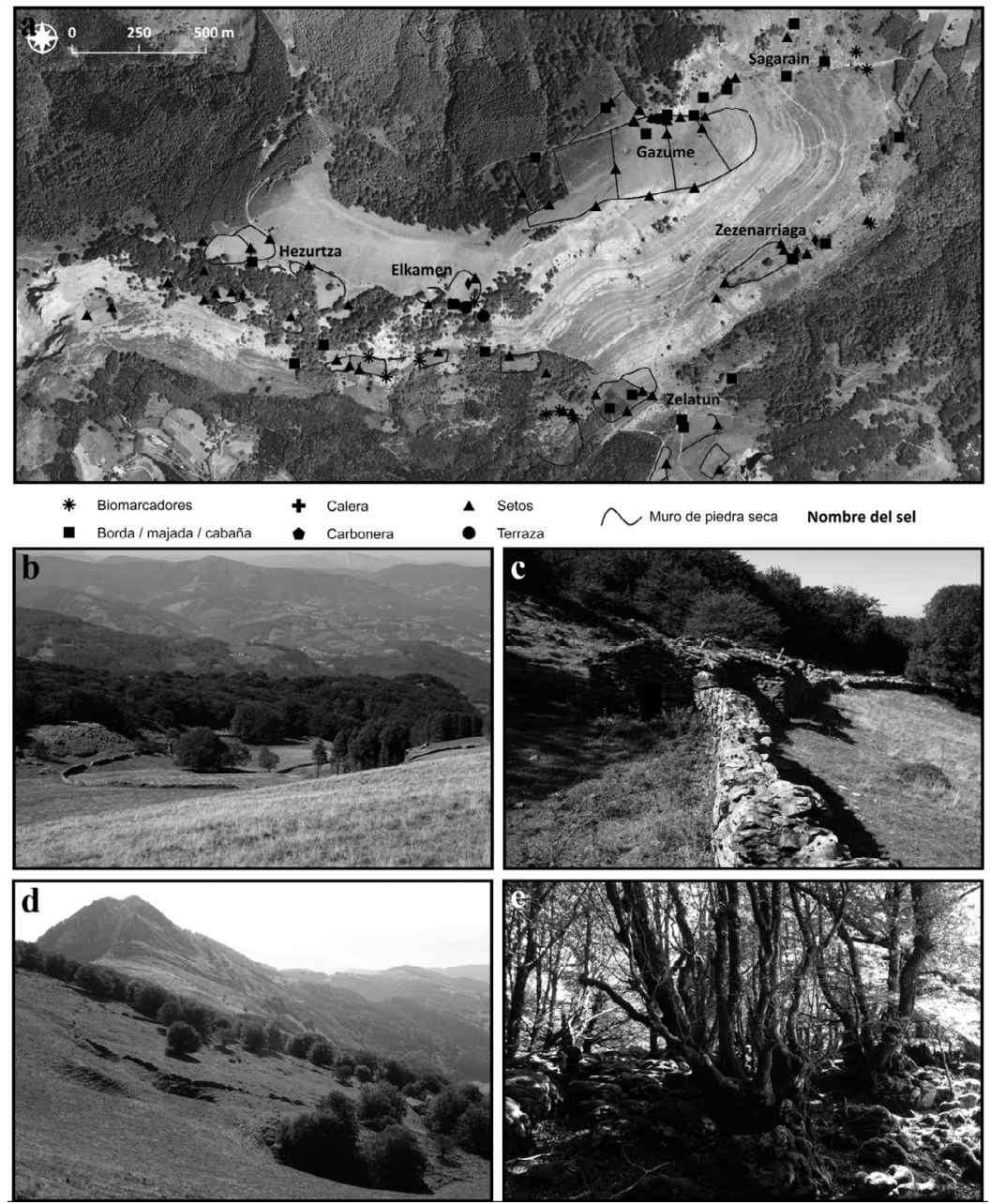

Nota: (a) planimetría de detalle de los seles comprendidos en esta unidad; (b) vista general del sel de Hezurtza; (c) cercado de piedra seca y borda abandonada en el sel de Hezurtza; (d) vista general del sel de Elkamen Nagusia; (e) restos de hayedo jaral en las inmediaciones del sel de Hezurtza.

Fuente: fotografías de Josu Narbarte.

La sentencia arbitral de 1452 menciona que el entorno de Elkamen es un espacio de aprovisionamiento de leña y madera para los habitantes de la tierra de Errezil ${ }^{35}$. Sin embargo, la importante predominancia de afloramiento de roca caliza, unida a un aprovechamiento ganadero que debió intensificarse al paso de la trashumancia ovina, han configurado un

35. AMZ, C.5.II.2.2. 
paisaje donde se alternan la vegetación asociada a roquedos calizos, lastonar de Brachypodium pinnatum (gramínea muy dura para el ganado) u otros pastos mesófilos; pastos petranos calcícolas formados por una vegetación herbácea de pequeño tamaño asociada a suelos pedregosos de escasa profundidad; y otros pastos montanos (Figs. 7a-7d). Los restos de hayedo calcícola o eutrofo han quedado relegados a las zonas más húmedas con gran pendiente y afloramientos rocosos, como las situadas en los márgenes de los seles de Zezenarriaga, Elkamen o Hezurtza, donde predomina el hayedo jaral o trasmochado desde la base (Fig. 7e).

\section{FIGURA 8}

\section{Límite de las parcelas rústicas en la actualidad}
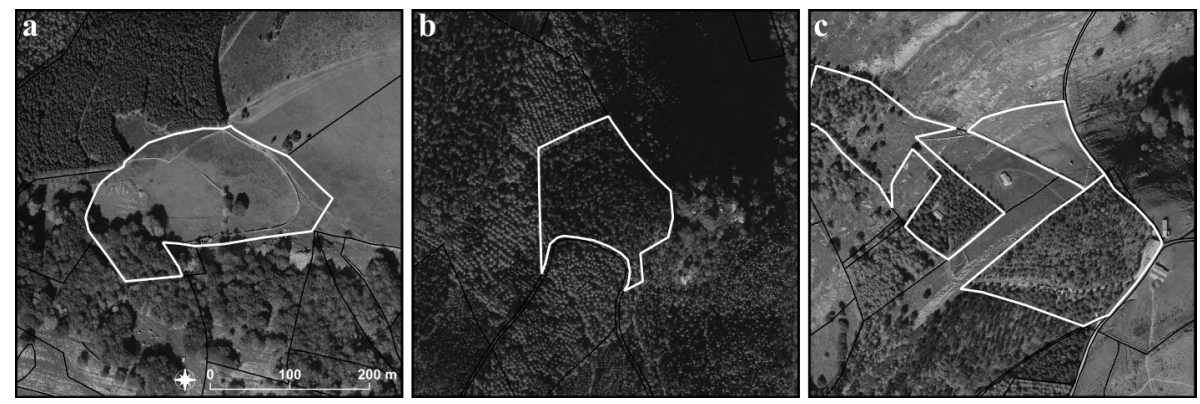

Nota: (a) Hezurtza; (b) Galleku; (c) Herniogurutzeaga o Zelatun.

Fuente: elaboración propia a partir de las bases cartográficas del Centro Nacional de Información Geográfica y la Diputación Foral de Gipuzkoa.

\section{CONSIDERACIONES FINALES}

La sierra de Hernio constituye un ejemplo de apropiación y gestión de un espacio de montaña por parte de dos comunidades rurales situadas en sus inmediaciones; apropiación que, durante al menos cuatro siglos, ejerció un notable, aunque desigual, impacto en la transformación del paisaje. La metodología planteada en este trabajo, basada en un análisis combinado de las fuentes de archivo y de la prospección sobre el terreno, ha permitido identificar numerosas huellas dejadas por las prácticas sociales del pasado en el paisaje actual, y relacionarlas con procesos históricos específicos. En contraste con su actual situación "marginal», la centralidad exhibida en el curso de cuatro siglos por este tipo de espacios compartidos, tanto en términos económicos como de sociabilidad, regulación y conflicto, debería invitar a la reflexión en torno al papel jugado por estas prácticas en la codificación y transmisión de las identidades colectivas y de las estrategias productivas de las comunidades campesinas preindustriales, así como en la desarticulación de tales vínculos sociales y su sustitución por el nuevo paradigma liberal. 
En términos generales, la evolución observada en los seles de Hernio entre los siglos XIV y XIX puede, así, vincularse a dos procesos simultáneos, que operaron a escalas cronológicas y espaciales diferentes. Por un lado, parece claro que la pauta a escala local consistió, desde el siglo XVI hasta el XVIII, en una progresiva expansión del espacio agrario a costa del monte, quizá estimulada por las potencialidades agronómicas introducidas por los nuevos cultivos americanos, en particular, el maíz. El ejemplo más claro de este proceso es la conversión de numerosos seles, en especial los invernizos, en caseríos de nueva planta. En un primer momento, este proceso parece haber sido impulsado por ciertas élites terratenientes con la anuencia de las corporaciones locales; estos caseríos serían interesantes no solo desde el punto de vista de las rentas que generaban, sino también de la comercialización de su producción. Sin embargo, en los siglos XVII y XVIII serán los propios concejos los que se involucrarán en esta dinámica de conversión de seles en caseríos, recabando directamente las rentas generadas por su arrendamiento. Este hecho lleva aparejada una desestructuración del uso vertical de la montaña, tal y como se había venido configurando desde el periodo bajomedieval por medio de una trashumancia local de ganado vacuno y porcino; proceso que puede interpretarse, también, como la desestructuración de una lógica de acción social de base comunitaria, fundamentada en la gestión colectiva de unos términos comunales, y su sustitución por un modelo mucho más descentralizado en el que la unidad doméstica individual irá acumulando en su seno cada vez más procesos productivos, gestionados ahora de manera autónoma.

Por otro lado, la evolución de los aprovechamientos en la sierra de Hernio también puede interpretarse en el marco del afianzamiento de una trashumancia ovina de largo recorrido, que conectará las cordilleras de la divisoria de aguas cantábrico-mediterránea (las sierras de Aralar, Aizkorri o Gorbea) con el litoral guipuzcoano y vizcaíno, a través de los pastos de altura que sobrevivieron a la expansión del caserío disperso. Es el caso, en particular, de los antiguos seles situados en torno a las cimas de Hernio y Gazume, donde los usos pastorales sostenidos hasta la actualidad se reflejan en la formación de un ecosistema muy particular, que no se da en el resto de la sierra. Esta trashumancia de largo recorrido, que requirió el desarrollo de una reglamentación supralocal y contribuyó a vertebrar el territorio mediante la integración de comarcas a menudo distantes entre sí, contrasta con el afianzamiento de una economía de base doméstica a escala local en torno a la dispersión del caserío, y refleja probablemente una estructura social y económica cada vez más compleja y polarizada.

De este modo, la enajenación generalizada de los bienes colectivos a finales del siglo XVIII y principios del siglo XIX aparece como el punto de llegada de un proceso de largo recorrido, en el que las viejas formas de gestión comunitaria basadas en el conflicto y la 
negociación fueron quedando, cada vez más, vaciadas de contenido en favor de unas lógicas sociales mucho más atomizadas y dinámicas. Es este un rasgo particular de los paisajes rurales en la vertiente cantábrica del País Vasco, que contrasta con otras regiones cercanas donde la lógica comunitaria mantuvo su vitalidad hasta fechas mucho más recientes. Así, la convergencia, durante varios siglos, de actores sociales, intereses y aprovechamientos muy diversos en un mismo espacio se traduce en lo que podríamos denominar un paisaje construido a retazos, actualmente abandonado en gran parte, cuyo carácter fragmentario y disperso dificulta enormemente aprehender las dinámicas de integración que pudieron operar en su codificación.

\section{AGRADECIMIENTOS}

Este trabajo se enmarca en el proyecto de investigación «Pasado y Presente del Paisaje Cultural de Montaña en la CAPV: desarrollo metodológico para el estudio arqueológico y puesta en valor de los espacios de bosque y pasto", financiado por el Departamento de Cultura y Política Lingüística del Gobierno Vasco. Asimismo, el artículo ha sido realizado en el marco de del proyecto "Agencia campesina y complejidad sociopolítica en el noroeste de la Península Ibérica en época medieval» (Ministerio de Economía, Industria y Competitividad, AEI/FEDER UE HUM2016-76094-C4-2-R), del Grupo de Investigación en Arqueología Medieval, Patrimonialización y Paisajes Culturales (Gobierno Vasco, IT1193-19) y del Grupo de Estudios Rurales (UPV/EHU-CSIC). Agradecemos, finalmente, las aportaciones y los comentarios realizados por cuatro revisores anónimos de esta revista que han contribuido a mejorar considerablemente el texto final.

\section{REFERENCIAS}

Achón, J. A. (1998). Historia de las vías de comunicación en Gipuzkoa 2: Edad Moderna (1500-1833). Donostia: Gipuzkoako Foru Aldundia.

AMO, E. DEL \& NARBARTE, J. (2018). Lejos del caserío: De la idealización a la (re)construcción del medio rural en la Euskal Herria atlántica. En VII Congreso Internacional de Agroecología: Libro de actas (pp. 949-957). Córdoba: Universidad de Córdoba.

Aragón, A. (2001). El bosque guipuzcoano en la Edad Moderna: Aprovechamiento, ordenamiento legal y conflictividad. Donostia: Aranzadi Zientzi Elkartea.

ARAGón, A. (2009). La ganadería guipuzcoana durante el Antiguo Régimen. Bilbo: Universidad del País Vasco/Euskal Herriko Unibertsitatea.

ARAGÓN, A. (2015). El sector agrario guipuzcoano en la encrucijada de los siglos XVI y XVII. Lurralde: Investigación y Espacio, (38), 89-116. 
ArenZANA, T. (2010). Los seles en Errenteria: Una primera aproximación. Bilduma: Revista del Servicio de Archivo del Ayuntamiento de Errenteria, (23), 179-214.

Arvizu, F. DE (1992). El conflicto de los Alduides (Pirineo navarro): Estudio institucional de los problemas de límites, pastos y facerías según la documentación inédita de los archivos franceses (siglos XVII-XIX). Iruña: Nafarroako Gobernua.

Ayerbe, R. (2019). Derecho municipal guipuzcoano: Ordenanzas, reglamentos y autos de buen gobierno (1310-1950). 5 vols. Donostia: Fundación para el Estudio del Derecho Histórico y Autonómico de Vasconia.

Bal, M. C., Rendu, C., Ruas, M. P. \& Campmajo, P. (2010). Paleosol Charcoal: Reconstructing Vegetation History in Relation to Agro-Pastoral Activities since the Neolithic: A Case Study in the Eastern French Pyrenees. Fournal of Archaeological Science, (37), 1785-1797.

BARANDIARAN, J. M. (1961). Bosquejo etnográfico de Sara, II: La población y el sistema de poblamiento. Anuario de Eusko Folklore, (18), 107-180.

BARRENA, E. (1989). La formación histórica de Guipúzcoa:Transformaciones en la organización social de un territorio cantábrico durante la época altomedieval. Donostia: Cuadernos Universitarios.

Bilbao, L. M. \& Fernández de Pinedo, E. (1984). La producción agrícola en el País Vasco peninsular, 1537-1850. Vasconia, (2), 83-198.

Cevasco, R. (2007). Memoria verde: Nuovi spazi per la geografía. Reggio Emilia: Diabasis.

Cevasco, R. \& Molinari, C. (2007). Microanalysis in Woodland Historical Ecology: Evidences of Past Leaf Fodder Production in NW Apennines (Italy). En Proceedings of the Conference Woodland Cultures in Time and Space:Tales from the Past, Messages for the Future, Thessaloniki (Greece), 3-7 September 2007. Atenas: Embryo.

DíAZ DE DuRAnA, J. R. (1998). Transformaciones en el aprovechamiento y titularidad de los seles en Guipúzcoa (1450-1550). Zainak, (17), 19-31.

Díaz De Durana, J. R. (2001). Para una historia del monte y del bosque en la Guipúzcoa bajomedieval: Los seles: Titularidad, formas de cesión y de explotación. Anuario de estudios medievales, 31 (1), 49-74.

Echegaray, B. DE (1933). La vecindad: Relaciones que engendra en el País Vasco. Revista Internacional de Estudios Vascos, 23 (3), 546-564.

ETXEZARRAGA, I. \& ARAGón, A. (2020). Entre la explotación pastoril y la forestal: La evolución en el uso y explotación de los seles en el País Vasco. En I. GrAu-SologestoA \& J. A. Quirós (Eds.), Arqueología de la Edad Moderna en el País Vasco y su entorno. Oxford: Archaeopress.

FERnÁNDEZ FERnÁNDEZ, J. (2011). Estudios multiescalares sobre la Alta Edad Media en elValle del Trubia (Asturias, España). Tesis doctoral. Oviedo: Universidad de Oviedo. 
FERNÁNDEZ FERNÁNDEZ, J. (2017). Arqueología de una aldea medieval y su espacio agrario: Villanueva de Santo Adriano (Asturias, noroeste de la península Ibérica). Historia Agraria, (72), 69-106.

FERNÁNDEZ FernÁNDEZ, J., Moshenska, G. \& IrIARTe, E. (2017). Archaeology and Climate Change: Evidence of a Flash-Flood during the LIA in Asturias (NW Spain) and its Social Consequences. Environmental Archaeology, 24 (1), 38-48.

Fernández Mier, M. (1995). Génesis del «territorio» en la Edad Media:Arqueología del paisaje y evolución histórica en dos concejos de la montaña asturiana: Miranda y Somiéu. Tesis doctoral. Oviedo: Universidad de Oviedo.

FERNÁNDEZ MIER, M. (1996). Análisis histórico-arqueológico de la configuración del espacio agrario medieval asturiano. Mélanges de la Casa de Velázquez, (32), 287-318.

FERNÁNDEZ MieR, M. (2013). Arqueología agraria del Norte peninsular: Líneas de investigación sobre un paisaje multifuncional: El ejemplo de Asturias. En A. GARCíA PoRRAS (Ed.), Arqueología de la producción en época medieval (pp. 419-442). Granada: Alhulia.

Fernández Mier, M. \& Fernández Hevia, J. M. (1998). Un microespacio en la montaña asturiana: Presorias. Arqueología y territorio Medieval, (5), 91-108.

Fernández Mier, M., Fernández Fernández, J., Alonso González, P., López Sáez, J. A., Pérez Díaz, S. \& Hernández Beloqui, B. (2014). The Investigation of Currently Inhabited Villages of Medieval Origin: Agrarian Archaeology in Asturias (Spain). Quaternary International, (346), 41-55.

Fernández Mier, M., Fernández Fernández, J., López Gómez, P., Martínez GaLlardo, C. \& Rodríguez PÉrez, S. (2019). Arqueología de las aldeas habitadas en Asturias: Los casos de Vigaña Arcéu y Villanueva de Santu Adrianu. Anejos de Nailos, (5), 99-119.

Galop, D., Houet, T., Mazier, F., Leroux, G. \& Rius, D. (2011). Grazing Activities and Biodiversity History in the Pyrenees: New Insights on High Altitude Ecosystems in the Framework of a Human-Environment Observatory. Pages, 19 (2), 53-55.

GARCía FERNÁNDEZ, E. (1997). La villa guipuzcoana de Cestona a través de sus ordenanzas municipales de 1483. Historia. Instituciones. Documentos, (24), 173-200.

Gassiot, E. (2016). Montañas humanizadas: Arqueología del pastoralismo en el Parque Nacional d'Aigüestortes $i$ Estany de Sant Maurici. Madrid: Organismo Autónomo de Parques Nacionales.

Gassiot, E. \& Pèlachs, A. (2017). La ocupación ganadera de los Pirineos occidentales de Catalunya en época romana e inicios de la Edad Media. Treballs d'Arqueologia, (21), 287-306.

Gogeascoechea, A. (2012). La colegiata de Cenarruza: Gestión y uso de sus seles. Lurralde: Investigación y espacio, (35), 31-52. 
Gogeascoechea, A., Juaristi, J. \& Moro, I. (2009). Del uso común del monte a la propiedad privada: Introducción al estudio de los Seles en Bizkaia. Lurralde: Investigación y espacio, (32), 15-46.

Gogeascoechea, A., Juaristi, J. \& Moro, I. (2010). El proceso histórico de ordenación de los seles de Bizkaia: Estandarización de las superficies y cambios en los usos del suelo. Lurralde: Investigación y espacio, (33), 37-95.

Gogeascoechea, A., Juaristi, J. \& Moro, I. (2011). Las formas de propiedad de los seles en Bizkaia. Lurralde: Investigación y espacio, (34), 151-188.

Martínez Montecelo, A. \& Rodríguez Fernández, J. (2013). Documentación sistemática del arbolado trasmocho: Un caso práctico en los Montes Altos deVitoria. Cuadernos de la Sociedad Española de Ciencias Forestales, (38), 149-158. (Ejemplar dedicado a las Actas del IV Encuentro de Historia Forestal).

Michel, M. (2006). El Pino Radiata en la Historia Forestal Vasca: Análisis de un proceso de forestalismo intensivo. Donostia: Aranzadi Zientzia Elkartea.

Michel, M. \& GIL SÁNCHEZ, L. (2013). La transformación histórica del paisaje forestal en la Comunidad Autónoma de Euskadi. Vitoria-Gasteiz: Eusko Jaurlaritzaren Argitalpen Zerbitzu Nagusia.

Moreno, D. (1990). Dal documento al terreno: Storia e archeologia dei sistemi agro-silvopastorali. Bologna: Il Mulino.

MujIKA, J. A. \& MoraZA, A. (2005). Establecimientos de habitación al aire libre: Los fondos de cabaña de morfología tumular: Características, proceso de formación y cronología. Veleia: Revista de prehistoria, historia antigua, arqueología y filologías clásicas, (22), 77-110.

MujiKa, J. A., Moraza, A. \& Moro, I. (2003). Contribución al estudio de las estructuras tumulares en arqueología: Entre la similitud morfológica y la disparidad de funciones. Veleia: Revista de prehistoria, historia antigua, arqueología y filología clásicas, (20), 243-272.

Palet, J. M., García Molsosa, A., Orengo, H. A. \& Polonio, T. (2017). Els espais altimontans pirenaics orientals a l'Antiguitat: 10 anys d'estudis en arqueologia del paisatge del GIAP-ICAC. Treballs d'Arqueologia, (21), 77-97.

Rementeria, D. \& Quintana, R. (2013). Los seles de Urdaibai: Paisaje, cultura y etnografía. Vitoria-Gasteiz: Eusko Jaurlaritzaren Argitalpen Zerbitzu Nagusia.

RENDU, C. (2003). La montagne d'Enveig, une estive pyrénéenne dans la longue durée. Perpignan: Trabucaire.

Rendu, C., Calastrenc, C., Le Couédic, M. \& Berdoy, A. (2016). Estives d'Ossau: 7000 ans de pastoralisme dans les Pyrénées. Toulouse: Le Pas d'oiseau.

Rendu, C., Passarrius, O., Calastrenc, C., Julia, R., Llubes, M., Illes, P., Campmajó, P., Jodry, C., Crabol, D., Bille, E., Conesa, M., Bousquet, D. \& Lallemand, V. (2015). Reconstructing Past Terrace Fields in the Pyrenees: Insights into Land Ma- 
nagement and Settlement from the Bronze Age to the Early Modern Era at Vilalta (1650 masl, Cerdagne, France). Fournal of Field Archaeology, 40 (4), 461-480.

Stagno, A. M. (2016). Archaeology of Commons: A Multidisciplinary Approach to the Reconstruction of Multiple Uses and Conflicts on European Uplands. En G. L. M. Burgers, S. J. Kluiving \& R. A. E. Hermans (Eds.), Multi-, Inter- and Transdisciplinary Research in Landscape Archaeology: Proceedings of the $3^{\text {rd }}$ International Landscape Archaeology Conference in Rome, Italy (2014). Amsterdam: Vrije Universiteit Amsterdam.

StAGNo, A. M. (2017). Archeologia e storia di uno spazio precario: Le colture temporanee tra pratiche collettive e appropriazione privata (Paesi Baschi, XV-XX secolo). Quaderni Storici, 52 (155), 499-534.

STAGNO, A. M. (2018). Gli spazi dell'archeologia rurale: Risorse ambientali e insediamenti nell'Appennino ligure tra XV e XXI secolo. Firenze: All'Insegna del Giglio.

STAGNo, A. M. (2019). Historia de un monte compartido: Un enfoque multi-disciplinar para el estudio de las formas históricas de apropiación de la tierra entre Zornoztegi y Udala. En J. A. QuiRós (Coord.), Arqueología de una comunidad campesina medieval: Zornoztegi (Álava) (pp. 481-514). Bilbo: UPV/EHU.

Stagno, A. M. \& Tejerizo, C. (2017). Montes de utilidad pública de Álava y Gipuzkoa: Sierra de Aizkorri (Parzonería General de Gipuzkoa y Álava, Oñati) y Llanada Alavesa oriental. Arkeoikuska, (16), 428-437.

TRUChuelo, S. (1997). La representación de las corporaciones locales guipuzcoanas en el entramado político provincial (siglos XVI-XVII). Donostia: Gipuzkoako Foru Aldundia.

Ugarte, F. M. (1976). Los seles en el valle de Oñate. Boletín de la Real Sociedad Bascongada de Amigos del País, 32 (3-4), 447-510.

ZALDUA, L. M. (1996). Saroeak Urnietan: Saroeen inguruko ikerketak zertan diren Euskal Herrian. Urnieta: Kulturnieta.

ZALDUA, L. M. (2006). Saroiak eta kortak: Mendialdeko antzinako gizartearen oinordeak. Urnieta: L. M. Zaldua.

ZALDUA, L. M. (2015). «Saroi» entitate geografikoaren banaketa, esanahia eta etorkia toponimiaren argitan. Fontes Linguae Vasconum, (119), 175-221. 
